American J. of Engineering and Applied Sciences 2 (1): 217-228, 2009

ISSN 1941-7020

(C) 2009 Science Publications

\title{
Improvement on the Design of a Cabinet Grain Dryer
}

\author{
Adzimah Kwasi Stephen and Seckley Emmanuel \\ Department of Mechanical Engineering, \\ Faculty of Engineering, University of Mines and Technology, Tarkwa, Ghana
}

\begin{abstract}
Problem statement: Grains are routinely seen dumped in villages and major cities during the peak of harvest. Therefore it is necessary that these grains are properly dried and stored to ensure availability and wholesomeness throughout the year. Advancements have taken place in the practice of drying since the first world war. Manufacturing methods have greatly improved production rate and the production line bottle-neck created by extended drying time inherent in the use old drying methods can no longer be tolerated. Main objectives of this study were to improve on the design of an existing cabinet grain dryer (to redesign the already existing cabinet grain dryer so as to: (i) Optimize efficiency at low cost (ii) Reduce total time of drying (iii) Produce viable and quality grain. Approach: The improvement on the design of the existing cabinet dryer had been achieved through proper focus on the selection of power source, materials and other design criteria for the various components of the existing one. The dryer consists of a cabinet containing trays in which the grains to be dried are spread. After the grains were loaded, the cabinet closed and heated air of about $35-40^{\circ} \mathrm{C}$ blown across the grains. Heat was supplied by an electrical heating coil and hot air was blown from the heater housing to the drying chamber by the aid of a fan. The dryer also consisted of a thermostat which turns off the machine if inlet temperature exceeds $40^{\circ} \mathrm{C}$. Results: The result of the improvement on the design of a cabinet grain dryer showed that; (i) It was less costly (ii) It was cheap to maintain since the fan is the only moving component and can hardly become faulty (iii) drying time of the grain was reduced (iv) The machine ergonomic; operation of the machine does not require specialization (v) The machine is safer to operate since the use of gas has been eliminated (vi) Time between two batches was reduced with the introduction of a trolley (vii) Energy for loading or unloading reduced since the trays can be loaded and unloaded outside the cabinet. Conclusion: Drying of grains safer since fire hazards were reduced owing to the use of gas in the previous design. Heater supplied the right quantity of heat and incorporates a fan which supplies right quantity of air needed to distribute this heat evenly to all grains in drying chamber. This made drying faster and grains are moderately dried.
\end{abstract}

Key words: Cabinet grain dryer, improvement on the existing design, drying of seed grains, factors affecting drying rate

\section{INTRODUCTION}

In West-Africa and other parts of the world, most of our locally made foods are made up of cereal grains such as maize, rice, millet. Most of these cereal grains are harvested at the peak of the rainy season, making preservation difficult and causing most of these grains to perish. This results in scarcity in the supply of the grains which leads to subsequent hunger and malnutrition. Meanwhile grains are routinely seen dumped in villages and major cities during the peak of harvest. Therefore it is necessary that these grains are properly dried and stored to ensure availability and wholesomeness throughout the year.
The history of drying goes back to the ages when man first saw the dire need to preserve his food items by removing as much moisture as possible. The early man relied on the energy from the sun to dry his food products. With time, drying with wood (coal) as a source of energy was developed as a complement or as an alternative to sun drying.

As a result of technological improvement, great advancements have taken place in the practice of drying since the First World War. Manufacturing methods have greatly improved production rate and the production line bottle-neck created by extended drying time inherent in the use old drying methods can no longer be tolerated. The old methods of drying under

Corresponding Author: Adzimah Kwasi Stephen, Department of Mechanical Engineering, Faculty of Engineering, University of Mines and Technology, Tarkwa, Ghana 
natural conditions in hot rooms, hot hearths and storages which involve long drying times, manhandling and little or no control of drying are completely unacceptable today.

The evolution of present day drying techniques has of course been a gradual one. It relied on developing drying methods applied to batches of products in intermittently operated dryers. Even today such methods and equipment are adequate, although possibly susceptible to improvement ${ }^{[4]}$.

The term "drying" from the industrial stand point is understood to represent the removal of liquid from a solid by thermal means. It can also means the removal of water from a suspension or solution of a solid. Such a definition clearly distinguishes thermal drying from mechanical dewatering as in the action of filters or centrifuges. It does not however, distinguish drying from the process usually referred to as evaporation as applied in commercial evaporators. In evaporators, heat is employed to remove liquid from solid solutions or suspensions in the liquid. In evaporation, the liquid occurs in larger proportions compared to the process of drying $^{[4]}$.

So far, the only known methods of drying grains in our localities are:

- By the traditional method which is laborious, time consuming, does not guarantee the safety of grains and is ineffective with unfavorable weather conditions

- The existing cabinet grain dryer which over dries the grains such that they cannot be planted and uses a lot of gas in the drying process

Therefore an improvement has to be done to eradicate the problems associated with the existing cabinet grain dryer.

The main objectives of this study are to improve on the design of an existing cabinet grain dryer (i.e., to redesign the already existing cabinet grain dryer so as to:

- Optimize efficiency at low cost

- $\quad$ Reduce total time of drying

- $\quad$ Produce viable and quality grain

\section{MATERIALS AND METHODS}

Regular visits were paid to the local farms where the existing grain dryer has been used. The machine was properly examined and the problems associated with its operation due to the shortcomings in its design were identified. The causes of these shortcomings were properly studied and procedures were carried out with the view of eliminating these shortcomings.
Recent developments of dryers:

Fluid bed drying: This the type of dryer in which individual grains are suspended and transported by air moving at a high velocity, 2-3 $\mathrm{m} \mathrm{sec}^{-1}$ can produce very evenly dried grain. Recent research in Philippines ${ }^{[11]}$ has indicated that the fluid bed dryer has promising potential for the rapid drying of rice paddy. Paddy at a depth of $100 \mathrm{~mm}$ can be dried from $24-15 \%$ moisture with air velocity of $2 \mathrm{~m} \mathrm{sec}^{-1}$ with no adverse effect in quality of grains.

Conduction drying: The conduction dryer consists of a metal floor heated to $50-90^{\circ} \mathrm{C}$ by circulation of water heated by a furnace burning agricultural waste. Paddy at depths of up to $60 \mathrm{~mm}$ could be dried from $24-18 \%$ moisture in $1-2 \mathrm{~h}^{[5]}$.

The ware house dryer: This dryer has been developed for use with a wide range of crops including maize and paddy. Its particular feature is the use of wind-powered vortex flow inducers as an alternative to conventionally powered fans for generating increased air flow over and around the grains.

Rotary drying: This method of drying was researched at the International Rice Research Institute (IRRI) in Manila Philippines.

Microwave and infrared dryers: When grain is subjected to electromagnetic energy, high potentials are generated between the interior and surface of individual grains. Moisture therefore migrates to the surface where it evaporates to the surrounding air. More uniform drying is possible compared to other conventional methods mentioned above ${ }^{[4]}$.

Drying of seed grain: If a grain is intended to be used as a seed, then it must be dried in a manner that preserves its viability. Seed embryos are killed by temperature greater than $40-42^{\circ} \mathrm{C}$ and therefore low temperature drying must be employed. Seed grains may be dried in any type of dryer provided that is operated at a low temperature and preferably with proper air flow. One of the commonest type of dryers used for this purpose is the mechanical batch-in-bin dryer. The small capacity version of the batch-in-bin dryer, otherwise known as the flat bed dryer, has been developed for local level use. It takes 6-12 h to complete the drying process. In the research that follows, effort is made to reduce drying time to about $2 \mathrm{~h}$. To understand the design better, the topics of food preservation and grain drying technology were reviewed ${ }^{[3]}$. 


\section{Overview of drying:}

Food preservation: Although it is undeniably important to increase the major yield of major crops in many developing countries, an even greater increase in the amount of food available for human consumption could be realized by using appropriate food preservation methods.

Most foods are preserved through canning, smoking, freezing, fermentation, use of chemical additive, sun drying and dehydration.

In using some of these methods, consideration is given to:

- Cost of labor

- Cost of energy

- Effects of method on food quality

- Minimum time storage

Sun drying happens to be the cheapest method of preserving food. This is because solar energy is utilized and facilities can be basically manufactured and maintained from materials that are locally available and within the economic reach of people. However, the major constraint with sun drying is the occasional disruption of drying by weather and climatic changes ${ }^{[5]}$.

Drying a product/food properly, gives it a better maximum storage period with little loss in the quality of the food compared to any of the above mentioned preservation methods. Thus there is the need for a mechanical dryer capable to dry effectively ${ }^{[5]}$.

Grain drying: Cereal grains are usually harvested at moisture content too high for safe storage. Thus drying is a necessity. A large amount of moisture has to be removed from wet grain to ensure that safe moisture content is achieved. This will reduce the rate of bacterial and fungal activity on the grains. It is clear that the length of time in which a grain can be safely stored varies with the moisture content of the crop. The moisture contents for different grains are shown in the Table $1^{[3]}$.

Table 1: Moisture contents for various grains

\begin{tabular}{llllll}
\hline Cereal & $\begin{array}{l}\text { Maximum } \\
\text { moisture } \\
\text { during } \\
\text { harvest }(\%)\end{array}$ & $\begin{array}{l}\text { Optimum } \\
\text { moisture } \\
\text { at harvest } \\
(\%)\end{array}$ & $\begin{array}{l}\text { Usual } \\
\text { moisture } \\
\text { at harvest } \\
(\%)\end{array}$ & $\begin{array}{l}\text { Required moisture } \\
\text { for safe storage }\end{array}$ \\
\hline 1--------------- \\
Barley & 30 & $18-20$ & $10-18$ & 13 & 5 years \\
Corn & 35 & $28-32$ & $14-30$ & 13 & $10-11$ \\
Oats & 32 & $15-20$ & $10-18$ & 14 & 11 \\
Rice & 30 & $25-27$ & $16-25$ & $12-14$ & $10-12$ \\
Rye & 25 & $16-20$ & $12-18$ & 13 & 11 \\
Sorghum & 35 & $30-35$ & $10-20$ & $12-13$ & $10-11$ \\
Wheat & 38 & $18-20$ & $9-17$ & $13-14$ & $11-12$ \\
\hline \multicolumn{2}{l}{ Source: Brooker et al. $^{[3]}$} & & & &
\end{tabular}

Importance of grain drying: Drying has one of the widest applications in both chemical and agricultural industries taking up a substantial percentage of annual investment in these industries. Therefore extensive research is done to provide new methods of drying which require minimum work space, minimum labor and high efficiencies. A lot of grains are lost during or before harvesting due to:

- $\quad$ Ear dropping

- Stalk getting broken

- Untimely harvesting whereby grains are either too wet or dry

- Wind effect

- Damage by animals, insects or birds in the field

Early harvesting coupled with recent grain drying methods can go a long way in preventing these losses. Prices of grains vary from month to month because even during storage, the quality of some grains is reduced due to improper moisture content. With controlled drying, the farmer can sell his grains at the market for higher prices without fear of deterioration or damage by pests during storage. Grain drying yields better quality grains and ensures the viability of the grains. It also permits earlier tilling of the ground and accurate planning of the planting and harvesting. Thus there is a dire need for laboratory grain drying facilities to ascertain the best suitable grain drying and storage conditions. Such research must also consider the resultant effect due to:

- Volume airflow

- Drying temperature

- Humidity

Drying time: This is the most important to Africa because we must not only mechanize our agricultural system, but also pursue rigorous agricultural policies to meet up the food demand of our fast growing population $^{[3]}$.

Rice drying: Rice is a cereal grain which is consumed world wide such that it can be considered as an ultimate gift to mankind. The demand for rice is so paramount that the farmers around the world, even in West Africa, grow two to three plantations per year. Hence, the drying calls for a controlled technique. Sun drying, although the most traditional and natural way of drying rice, does not yield the best production since it cannot be effectively controlled. Hence, the need for a mechanical grain dryer as rain damage and other climatic changes can take a heavy toll on the farmers who solely rely on the sun for drying. 
Theory of drying: The main purpose of drying is to extend the shelf life of food by the reduction in the water activity which inhabits microbial growth. However, the processing temperature will not normally be sufficient to cause inactivation.

Although drying increases the storage value of grains, it also causes reduction in eating quality and nutritive value of food. To minimize such detrimental effect, drying equipment should be appropriately designed to ensure sufficient drying rates. In the design considerations, it is important to take into consideration the moisture content of the grain to be dried. The following terminologies are considered in this regard.

Expression of moisture content: Moisture content can be expressed in two ways, dry or wet basis. The expressions are given:

$$
\begin{array}{ll}
\text { Moisture content (wet basis) }= & (\text { Mass of water/Mass of } \\
& \text { sample }) \times 100 \\
= & \text { Mass of water }+ \text { Mass } \\
\text { Mass of sample } & \text { of dry solid } \\
\text { Moisture content (dry basis) }= & (\text { Mass of water/Mass of } \\
& \text { dry solid }) \times 100
\end{array}
$$

Water activity (Aw): Water activity is the measure of the availability of water in reactions such as chemical, microbiological and enzymatic reactions. The water in a food will exert a vapour pressure. The value of this pressure will depend on the amount of water present, the temperature and composition of the food. Water activity can be defined as the ratio of the vapour pressure exerted by the food to saturated vapour pressure of water at the same temperature.

Aw = Vapor pressure of water exerted by food/Saturated vapour pressure at the same temperature

Water activity is related to relative humidity by the expression below:

Aw = Relative Humidity $(\mathrm{RH}) / 100$

The easiest way of determining Aw is to place the food into a sealed container and to measure the relative humidity of the air in the container once equilibrium has been reached ${ }^{[6]}$.

\section{Classification of water in grains:}

Free water: It is the type of water which is removable at a given temperature and humidity. This can often be thought of as the second layer of moisture attached to the grain surfaces.
Bound water: It is the type which exerts a vapour pressure less than that of pure water. At a given temperature the water may become bound by retention in:

- Small capillaries by other liquid solutions in plant cell

- Small capillaries in fiber by homogenous solutions throughout the solid

Water can also be bound by chemical and physical adsorption on solid surface. It can often be thought of as the first layer of water attached to the surface.

Unbound water: It is that water in excess of the equilibrium moisture content corresponding to the saturation humidity ${ }^{[3]}$.

Method of measuring moisture content: The methods of determining moisture content of grains can be divided into two broad categories, direct and indirect. Direct methods determine the water content by removing moisture. In contrast, indirect methods require the measurement of an electrical property of the grain, either conductance or capacitance. Direct methods are however considered to provide true measurement of moisture content.

\section{Direct methods:}

Chemical reaction: It consists of extraction of water from grain chemically. It depends on the reaction of iodine with water in presence of sulphur (IV) oxide ${ }^{[9]}$.

Heating (oven) method: The moisture content of the grain is determined by subtracting the dry weight of the sample from the initial weight of the sample (weight of sample before drying:

- Distillation: It involves mixing ground grain samples with foulene and boiling the moisture. The water comes out as vapour and the volume is measured. The measured volume of vapour determines the moisture content of the grains

- Infrared and microwave radiation: Both infrared and microwave energies are used to evaporate the moisture in a given sample. Moisture measurement based on either type requires the use of ground samples

Indirect methods:

Resistance: This type of measurement involves a moisture meter which measures the electrical resistance of a grain sample to an electrical current. A whole 
sample is placed between two electrodes in a compression cell. The sample must be compressed to a known and constant value for accurate measurement.

Capacitance: A sample is poured into an enclosure with walls that act as condenser plates activated by high frequency current. Precise weighing and correction of temperature differing from $77^{\circ} \mathrm{F}\left(2.5^{\circ} \mathrm{C}\right)$ are the requirements for accurate measurement. A calibration chart is needed for every grain type. Capacitance meters are generally more accurate over a wider range of moisture than resistance meters.

Chemistry of drying: During drying, it is necessary to remove free moisture from the surface and also from the interior of the material. When hot air is blown over the grain, heat is transferred to its surface and the latent heat of vaporization causes water to evaporate. Water vapour diffuses through a boundary film of air. This creates a region of lower vapour pressure at the surface of the grain and a water vapour gradient is established from the most interior part of the grain to the dry air ${ }^{[9]}$.

The gradient provides the driving force for removal of water from the food. Water moves to the surface by the following mechanisms:

- Liquid movement by capillary force

- Diffusion of liquids caused by difference in the concentration of solutes in different regions of the grain

- Diffused liquids are absorbed in a layer at the surface of solid components of the grains

Water vapor diffusion in air spaces within the grains caused by pressure gradient.

Difference in temperature is however responsible for the created pressure gradient, thus in defining the properties of air required for drying, we must understand two fundamental temperatures, namely Dry temperature and Wet temperature.

Second phase or constant rate period: During this period, drying takes place at the surface of the grain and is similar to evaporation of moisture from free water surface. The rate of evaporation depends largely on the surroundings and only little on the type of grain. The period ends when the moisture content is below that necessary to replenish the moisture of the surface that is at the critical moisture content (Fig. 1). The three characteristics of air that are necessary for successful drying in the constant rate period are ${ }^{[3]}$ :

- A moderately high dry bulb temperature

- A low relative humidity

- A high air velocity

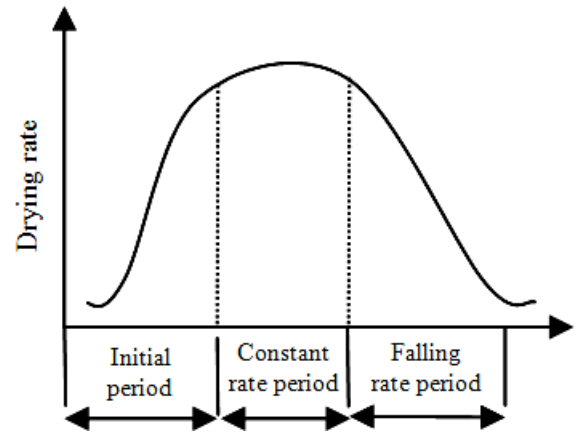

Fig. 1: The drying curve ${ }^{[3]}$

Third phase or falling rate period: It is the phase during which migration of moisture from inner interstices of each particle to the outer surface becomes the limiting factor that reduces the drying rate.

Since grains belong to the class of hydroscopic food (materials that contain bound water) they have two falling rate periods namely; first falling rate periods and second falling rate period:

- First falling rate period: It represents a condition whereby the grain surface is no longer capable of supplying sufficient moisture to saturate the air in contact. It is under the condition that the rate of drying depends very much on the mechanism by which the moisture from the grain is transferred to the surface. At the conclusion of this falling rate period, it may be assumed that the surface is dry

- Second falling rate period: At this stage the vapour reaches the surface by molecular diffusion. The forces controlling the vapour diffusion will determine the final rate of drying and this will be largely independent of the conditions outside the material involved:

Thus in drying grains, two processes are

- The transfer of heat to evaporate the water contained in the grain

- The transfer of mass as internal moisture and evaporated liquid. The internal mechanisms which control moisture are diffusion, capillary action, shrinkage, vapour pressure, gravity and vaporization

The rate of drying depends on the proportion of air (dry bulb temperature, wet bulb temperature and relative humidity), the velocity of air, surface heat transfer coefficient and the properties of food being dried. 
To determine the time required to achieve the desired reduction in product moisture content, the rate of moisture removed from the product must be determined ${ }^{[3]}$.

Factors affecting drying rate: The factors that affect drying rate are:

- Relative humidity of air

- Time of drying

- Method of heat supply

- Grain depth

- Feed rate

- Temperature of inlet and outlet air

- Drying operation

- Moisture content of grain $^{[3]}$

Drying operation: Dying operation can either be continuous or in batches. These terms are applied specially from the point of view of the substance being dried.

Continuous drying is well suited for large scale drying operations and such operation is integrated with a continuous process for manufacturing finished products, for example, drying of maize to the production of cornflakes. There is no intermediate storage.

However, continuous dying equipment is expensive and high requirement is needed. The sudden exposure of grain to high temperature may be detrimental to seed viability.

Classes of continuous driers include:

- Tunnel dryers

- Rotating shelf dryers

- Trough circulation dryers

- Rotary dryers

In batch drying, equipment is operated intermittently or cyclically under unsteady state conditions. The dryer is charged with a substance which remains in the equipment until it is dry. After the drying is finished, the dryer is emptied and replaced with a fresh batch. This may result in cold spots within the cabinet that will cause product in certain areas of the dryer to have higher final moistures. The batch dryers are less expensive and limited to small scale operation and to drying valuable food crops whose total cost would not be affected much by the cost of the drying operation. This makes it preferable and appreciated by local farmers.

Design procedures of the cabinet grain dryer:

Cabinet grain dryers: Cabinet grain dryers operate on the principle of batch drying. They are the commonest types of dryers used in the small scale grain drying industries. They cover a wide range of grains and are relatively inexpensive to purchase as compared to other drying methods.

Components of the existing cabinet grain dryer: The existing cabinet grain dryer (Fig. 2) is made up of three major components, namely:

- The energy (gas) supplier

- The burner

- The drying chamber

- The Energy Supplier

This component is made up of two gas bottles and hoses connected to them. The gas bottles have a capacity of $75 \mathrm{~L}$ each and are enclosed in a metallic box. The hoses supply gas from the gas bottles to the burner where heat is generated.

The burner: The dryer uses a five chamber burner system in which heat is being produced. The burner incorporates switches with a sparking mechanism that ignites the gas when it is fed from the gas bottle.

The drying chamber: The drying chamber is the part of the dryer where the grains to be dried are fed and drying takes place. The grains are fed into trays first and these trays are then fed into the drying chamber. The heat supplied from the burner is transferred to the drying chamber by the principle of conduction.

Principle of operation of the existing cabinet grain dryer: The grains which are to be dried are loaded into the trays and the trays are then fed into the drying chamber and the door is closed sealing the system.

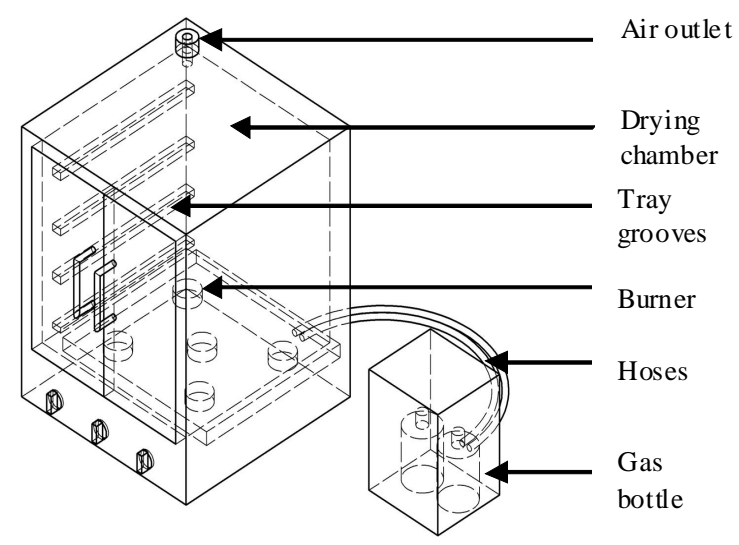

Fig. 2: Diagram of the existing cabinet grain dryer 
The trays may have solid or perforated bottom depending on the food particle size. The gas knob is then opened for gas to flow through the hoses to the burner.

The burner incorporates a switch which has a sparking mechanism when turned clockwise. This spark produced by the clockwise rotation of the switch ignites the gas and produces a light blue flame which heats up the drying chamber. When moisture from grains is vaporized, they pass through an outlet to the surrounding.

Problems identified with the existing design of the existing cabinet grain dryer: Poor Heat Distribution of the Drying Chamber.

Grains in the trays at the bottom dry faster than grains at the top of the drying chamber. This causes:

- Over-drying of grains at the bottom of the drying chamber which destroys their embryos such that they cannot be planted

- Longer drying time for the grains at the top of the drying chamber

- Over-drying of grains at the bottom and, longer drying time for the grains at the top of the drying chamber render the dried grains differ in texture and for that matter affect their overall quality

- Reduction in quality of grains since the over-dried grains may not be sold for good prices because they cannot be planted or used as seed grains

Hazards associated with the use of the existing cabinet grain dryer: This design is prone to give frequent fire hazards. These hazards are brought about by the unsafe conditions and actions as listed:

- Leakages from gas bottles

- Leakages from hoses

- Smoking in drying room

- Carrying out hot work operations in the drying room.eg. welding, grinding to mention a few

Ergonomics: Loading and unloading of trays are very stressful to workers especially when the trays are hot.

The proposed improved design of the existing cabinet grain dryer: The improvement on the existing design of the existing cabinet grain dryer has been carried out based on the problems associated with the existing design i.e., to improve upon the heat distribution, safety and ergonomics of the machine.

\section{Design considerations:}

- Drying of grains to take $30 \mathrm{~min}$

- $\quad$ Rice is used as an example to cover a large range of grains
- The inlet temperature of air has been made not to exceed $40^{\circ} \mathrm{C}$ in order to prevent destruction of grains

- With respect to ergonomics, the trolley has been made to be high enough to allow easy rolling in and out of the cabinet without unnecessary bending of the operator

Components of the improved dryer: The dryer consists of six major components, namely:

- The drying chamber

- The trolley and trays

- The heater

- The fan/blower

- The control panel

The drying chamber: The drying chamber has a length of $0.8 \mathrm{~m}$, width of $0.8 \mathrm{~m}$ and height of $1.2 \mathrm{~m}$. It is made of mild steel. The selection of mild steel in this regard is due to its strength and heat transfer properties. Inside the drying chamber is painted with silver to reduce heat loss by radiation and each side of the chamber is insulated to reduce heat loss.

The trolley: The trolley has a length of $0.76 \mathrm{~m}$, width of $0.76 \mathrm{~m}$ and height of $0.8 \mathrm{~m}$. The trolley is designed in such a way that it allows easy insertion of individual trays at a distance of $0.1 \mathrm{~m}$ apart and has tyres for easy movement of trays. The material for the trolley is mild steel. The reason for selecting this material is due to the structural properties and its weldability.

The trays: The trays are made of mild steel and have a length $0.74 \mathrm{~m}$, width $0.74 \mathrm{~m}$ and depth of $0.1 \mathrm{~m}$. The tray base could be solid or made of fine wire gauze which allows heated air to pass through grains (Fig. 3).

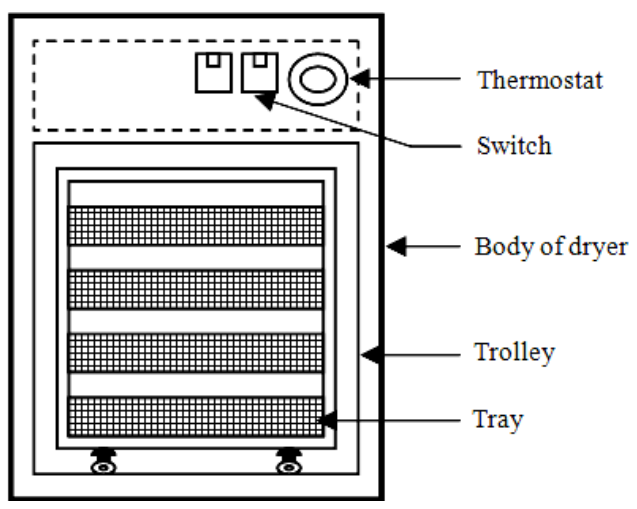

Fig. 3: Diagram showing the arrangement of the trays in the drying chamber 
The heater: The heater supplies heat for the drying of the grains and will be electrically powered. To ensure that the grains are properly dried within the specified drying temperature $\left(40^{\circ} \mathrm{C}\right)$, the right power rating must be determined ${ }^{[6]}$.

Selection of the heater: Length, width and height of drying chamber are $0.8,0.8$ and $1.2 \mathrm{~m}$ respectively:

Volume of drying chamber $=0.8 \times 0.8 \times 1.2=0.768 \mathrm{~m}^{3}$

Length, width and height of trays are $0.74 \mathrm{~m}, 0.74$ $\mathrm{m}$ and $0.1 \mathrm{~m}$ respectively:

\begin{tabular}{|c|c|}
\hline Volume of one tray & $\begin{array}{l}=0.74 \times 0.74 \times 0.1 \\
=0.05476 \mathrm{~m}^{3}\end{array}$ \\
\hline $\begin{array}{l}\text { Distance between subsequent } \\
\text { trays }\end{array}$ & $=0.1 \mathrm{~m}$ \\
\hline Intended drying time & $=30 \mathrm{~min}$ \\
\hline Height at which grains will & \\
\hline fill the trays & $=0.08 \mathrm{~m}$ \\
\hline Volume of grains per tray & $\begin{array}{l}=0.08 \times 0.74 \times 0.74 \\
=0.043808 \mathrm{~m}^{3}\end{array}$ \\
\hline Total volume of grains & $\begin{aligned}= & \text { Number of trays } \times \\
& \text { volume per tray } \\
= & 4 \times 0.043808 \\
= & 1.75232 \times 10^{-1} \mathrm{~m}^{3}\end{aligned}$ \\
\hline $\begin{array}{l}\text { Using rice as an example, } \\
\text { bulk density of rice } \\
\text { Total mass of rice }\end{array}$ & $\begin{array}{l}=768.96 \mathrm{~kg} \mathrm{~m}^{-3} \\
=\text { bulk density } \times \text { volun }\end{array}$ \\
\hline rotal mass or nce & 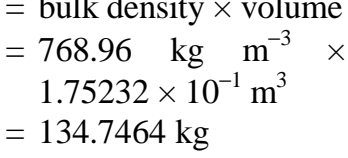 \\
\hline
\end{tabular}

Moisture content $=\left\{\left(\mathrm{M}_{\mathrm{w}}-\mathrm{M}_{\mathrm{d}}\right) / \mathrm{M}_{\mathrm{w}}\right\} \times 100$

Where:

$\mathrm{M}_{\mathrm{w}}=$ Mass of wet grain

$\mathrm{M}_{\mathrm{d}}=$ Mass of dry grain

From the moisture content table, optimum moisture content for rice when harvested $=27 \%$. Therefore:

$$
\begin{aligned}
& \left\{\left(\mathrm{M}_{\mathrm{w}}-\mathrm{M}_{\mathrm{d}}\right) / \mathrm{M}_{\mathrm{w}}\right\} \times 100 \quad=27 \\
& \left\{\left(134.7464-M_{d}\right) / 134.7464\right\} \times 100=27 \\
& \mathrm{M}_{\mathrm{d}} \quad=134.7464-36.3815 \\
& \text { Mass of water } \quad=\text { Mass of wet grain } \\
& \left(\mathrm{M}_{\mathrm{w}}\right) \text {-Mass of dry } \\
& \text { grain }\left(\mathrm{M}_{\mathrm{d}}\right) \\
& \text { Mass of water } \quad=134.7464-98.3649 \\
& =36.3815 \mathrm{~kg}
\end{aligned}
$$

Quantity of heat required to remove moisture content:

$$
(\mathrm{Q})=\mathrm{M} \times \mathrm{C}_{\mathrm{p}} \times \Delta \mathrm{T}
$$

Where:

$\mathrm{M}=$ Mass of water

$\mathrm{C}_{\mathrm{p}}=$ Specific heat capacity of water

$\Delta \mathrm{T}=$ Temperature difference between dried grains and the initial temperature of the dryer

Assuming the dryer is initially at $5^{\circ} \mathrm{C}$ and since the temperature for good grain drying should not exceed $40^{\circ} \mathrm{C}$, temperature difference $=(40-5)^{\circ} \mathrm{C}=35^{\circ} \mathrm{C}$.

Specific heat capacity

of water

$=4.182 \mathrm{~kJ} \mathrm{kgK}^{-1}$

Mass of water

$=36.3815 \mathrm{~kg}$

Q

$=36.3815 \times 4.182 \times 35$

$=5.3252 \times 10^{3} \mathrm{~kJ}$

Power

$=$ Quantity of heat/time $(\mathrm{sec})$

Intended drying time $=30 \mathrm{~min}$

Power

$=30 \times 60 \mathrm{sec}$

Power

$=5.322 \times 10^{3} /(30 \times 60)$

$=2.9584 \mathrm{~kW}$

From the above calculation a heating element of about $3 \mathrm{~kW}$ should be used.

The fan/blower: The fan aids in heat distribution by drawing ambient air from the surrounding to the heater housing and discharging heated air to the drying chamber. A proper fan has to be selected so that proper distribution of heat is achieved ${ }^{[6]}$.

Selection of the fan:

Work done by heater $=$ Work done on air

Work done by heater $=3 \mathrm{~kW}$

Work done on air $=$ Mass flow rate of air $\times$ Specific heat capacity of air $\times$ Temperature difference

Specific heat capacity of air $=1.005 \mathrm{~kJ} \mathrm{kgK}^{-1}$

Equating (1) and (2) we have:

Mass flow rate $\times$ Specific heat capacity $\times$ Temperature difference $=3 \times 10^{3} \mathrm{~W}$

Mass flow rate $=\left(3 \times 10^{3}\right) /\left(1.005 \times 10^{3} \times 35\right)$

From appendix, density

of air at $40^{\circ} \mathrm{C}$

Specific volume (v)

$$
=0.0853 \mathrm{~kg} \mathrm{sec}^{-1}
$$$$
=1.127 \mathrm{~kg} \mathrm{~m}^{-3}
$$$$
=1 / 1.127
$$$$
=0.8873 \mathrm{~m}^{3} \mathrm{~kg}^{-1}
$$ 


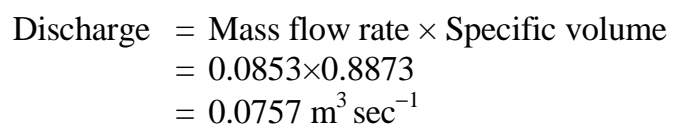

Converting the value of the discharge obtained to cubic foot per min $(\mathrm{cfm})$ for standard fan selection, we have ${ }^{[2,7,10]}$ :

$\begin{aligned} 1 \mathrm{cfm} & =4.91747 \times 10^{-4} \mathrm{~m}^{3} \mathrm{sec}^{-1} \\ 0.0757 \mathrm{~m}^{3} \mathrm{sec}^{-1} & =153.94 \mathrm{cfm}\end{aligned}$

Velocity of air through grain: Air flow rate/Cabinet area $\left[\mathrm{cfm} / \mathrm{ft}^{2}\right]$ :

Length of drying

$\begin{array}{lll}\text { chamber } & =0.8 \mathrm{~m} & =2.6247 \mathrm{ft} \\ \text { Area of floor } & =2.6247 \times 2.6247 & =6.889 \mathrm{ft}^{2} \\ \text { Velocity } & =153.94 / 6.889 & =22.345 \mathrm{cfm} / \mathrm{ft}^{2}\end{array}$

From Appendix A, corn has moisture content close to that of rice so we assume a static pressure of 0.22 inch per foot of depth.

Total depth of grains $=$ Number of trays $\times$ Height at which grains fill each tray (ft)

Height at which grains

will fill the tray $\quad=0.08 \mathrm{~m}=0.2625 \mathrm{ft}$

Total depth of grains $\quad=4 \times 0.2625=1.05 \mathrm{ft}$

Static pressure loss

due to resistance to

air flow by grains

$$
\begin{aligned}
& =\text { Total depth of grains } \times \\
& \text { Static pressure per foot } \\
& =1.05 \times 0.22 \\
& =0.231 \text { inch of water }
\end{aligned}
$$

If there are foreign materials in the grains, we multiply the static pressure by $1.3-1.5$.

The presence of foreign materials in the grains is inevitable; therefore:

Static pressure loss due to resistance to air flow by grains $=1.5 \times 0.231=0.3465$ inches of water:

Pressure loss due to friction in heater housing = $\lambda \mathrm{IU}^{2} / 2 \mathrm{gh}$ (Darcy's equation)

Where:

$\lambda=$ Coefficient of friction

1 = Length of heater housing

$\mathrm{h}=$ Height of heater housing $=0.4 \mathrm{~m}$

$\mathrm{U}=$ Linear velocity of air

$\mathrm{g}=$ Acceleration due to gravity

Applying the momentum equation:
Mass flow rate $=\rho_{1} \times A_{1} \times U_{1}=\rho_{2} \times A_{2} \times U_{2}$

Where:

$\mathrm{A}_{1}=$ Area of heater housing

$\mathrm{A}_{2}=$ Area of drying chamber

$\rho_{1}=$ Density of air in heater housing

$\rho_{2}=$ Density of air in dying chamber

Since mass flow rate $=0.0853 \mathrm{~m}^{3} \mathrm{sec}^{-1}$ (from

Area of heater housing $=0.4 \times 0.4$ previous calculations)

$=0.16 \mathrm{~m}^{2}$

$\mathrm{U}_{1} \quad=0.0853 /(1.127 \times 0.16)$

$=47.3048 \mathrm{~m} \mathrm{sec}^{-1}$

Reynolds number $\quad=\left(\mathrm{U}_{1} \times \mathrm{l}\right) / v$ where $v$ is the kinematic viscosity

From appendix $\mathrm{C}$ kinematic viscosity of air at $40^{\circ} \mathrm{C}$ is $1.69 \times 10^{-5} \mathrm{~m}^{2} \mathrm{sec}^{-1}$

Reynolds number $=(47.3 \times 0.4) / 1.69 \times 10^{-5}$

$$
=1.1195 \times 10^{6}
$$

Flow is turbulent since $\mathrm{Re}>4000$.

Relative roughness for steel $=3 \times 10^{-5}$

Checking the moody diagram

(Appendix B), coefficient of friction $\lambda=0.015$

Substituting into the Darcy's equation:

$\mathrm{h}_{2}=\left(0.015 \times 47.3^{2} \times 0.4\right) /(2 \times 9.81 \times 0.4)$

$=1.71 \mathrm{~m}$ of air

Converting the above values from meters of air to meters of water we use the equation:

$$
\mathrm{h}_{\mathrm{w}}=\left(\rho_{\mathrm{a}} \times \mathrm{h}_{2}\right) / \rho_{\mathrm{w}}
$$

Where:

$\mathrm{h}_{\mathrm{w}}=$ Pressure head in meters of water

$\rho_{\mathrm{a}}=$ Density of air at $40^{\circ} \mathrm{C}$

$\rho_{\mathrm{w}}=$ Density of water at atmospheric pressure

$\mathrm{h}_{\mathrm{w}}=(1.127 \times 1.71) / 992.2=1.9423 \times 10^{-3} \mathrm{~m}$ of water have:

Converting the value above to inches of water we

$1.9423 \times 10^{-3} \mathrm{~m}$ of water $\quad=0.03$ inches of water

Loss due to sudden enlargement $=\mathrm{U}_{1}^{2} / 2 \mathrm{~g}\left\{1-\left(\mathrm{A}_{1} / \mathrm{A}\right)\right\}$

$\mathrm{A}_{1}=0.4 \times 0.4=0.16 \mathrm{~m}^{2}$

$\mathrm{A}_{2}=0.8 \times 0.8=0.64 \mathrm{~m}^{2}$

$\mathrm{h}_{3}=47.3^{2} / 19.62\{1-(0.16 / 0.64)\}=85.5233 \mathrm{~m}$ of water 
Am. J. Engg. \& Applied Sci., 2 (1): 217-228, 2009

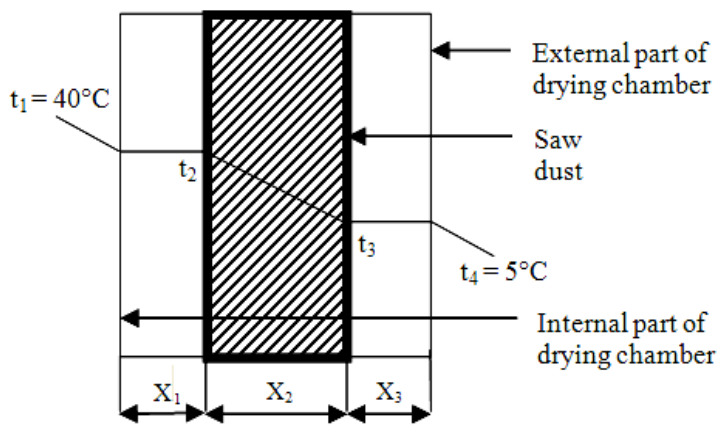

Fig. 4: Insulation of drying chamber using saw dust ${ }^{[6]}$ have:

Converting the above value to inches of water, we

$$
\begin{aligned}
85.5233 \mathrm{~m} \text { of water }= & 3.8228 \text { inches of water } \\
\text { Total static pressure }= & \mathrm{h}_{1}+\mathrm{h}_{2}+\mathrm{h}_{3}=0.231+0.03 \\
& +3.8228=4.0838 \text { inches of } \\
& \text { water } \\
\text { Fan horse power } & (\text { Air flow } \times \text { total } \\
& \text { pressure }) /(6320 \times \times \\
& \text { efficiency })
\end{aligned}
$$

From research, most industrial fans have efficiency ranging from $70-85 \%$.

Using an efficiency of $85 \%$

$$
\begin{aligned}
\text { Fan horse power } & =(153.94 \times 4.0838) /(6320 \times 0.85) \\
& =0.117 \mathrm{Hp}
\end{aligned}
$$

An axial flow fan with $0.2 \mathrm{Hp}$ and 4.0838 inch of water static pressure should be used. An axial flow fan is used to ensure proper distribution of air to the drying chamber and for effective heat distribution ${ }^{[6]}$.

Insulation of the drying chamber: Different materials are available for insulation but considering the drying temperature, availability and cost of insulating material, saw dust has been chosen for installation (Fig. 4).

Assuming a loss of $4 \%$ of the quantity of heat produced, we can calculate the required thickness for saw dust:

$\mathrm{X}_{1}=\mathrm{X}_{3}=5 \mathrm{~cm}$

Quantity of heat per sec $=3000 \mathrm{~W}$ (from previous calculations):

$4 \%$ of the quantity of heat produced $\sec ^{-1}=q=120 \mathrm{~W}$

$$
\begin{aligned}
& \text { Quantity of heat lost unit }{ }^{-1} \text { area }(\mathrm{q})=\lambda_{1} / \mathrm{X}\left(\mathrm{t}_{1}-\mathrm{t}_{2}\right) \\
& =\lambda_{2} / \mathrm{X}_{2}\left(\mathrm{t}_{2}-\mathrm{t}_{3}\right) \\
& =\lambda_{3} / \mathrm{X}_{3}\left(\mathrm{t}_{3}-\mathrm{t}_{4}\right) \\
& =\mathrm{U}\left(\mathrm{t}_{1}-\mathrm{t}_{4}\right)
\end{aligned}
$$

Where:

$\lambda_{1}$ and $\lambda_{3}=$ Heat transfer coefficient for mild steel $=46 \mathrm{~W} / \mathrm{m}^{\circ} \mathrm{C}$

$\lambda_{2}=$ Heat transfer coefficient of saw dust $=0.08 \mathrm{~W} / \mathrm{m}^{\circ} \mathrm{C}$

$\mathrm{X}_{1}, \mathrm{X}_{3}$ and $\mathrm{X}_{2}=$ The respective thicknesses of mild steel and sawdust

Equation 1 and 2 we have:

$120=46 / 0.05\left(40-\mathrm{t}_{2}\right)$

Solving for $\mathrm{t}_{2}$, in the above equation, we have:

$$
\begin{aligned}
\mathrm{t}_{2} & =40-0.13=39.87^{\circ} \mathrm{C} \\
\mathrm{q} & =\lambda_{3} / \mathrm{X}_{3}\left(\mathrm{t}_{3}-\mathrm{t}_{4}\right) \\
120 & =46 / 0.05\left(\mathrm{t}_{3}-5\right) \\
\mathrm{t}_{3} & =5.13{ }^{\circ} \mathrm{C} \\
\mathrm{q} & =\lambda_{2} / \mathrm{X}_{2}\left(\mathrm{t}_{2}-\mathrm{t}_{3}\right) \\
120 & =0.08 / \mathrm{X}_{2}(39.87-5.13) \\
\mathrm{X}_{2} & =0.0231 \mathrm{~m}
\end{aligned}
$$

Saw dust $0.0231 \mathrm{~m}$ thick should be used as the insulating material to achieve a minimal heat loss of $4 \%$ from the drying chamber ${ }^{[2,6,7,10]}$.

The control panel: The control panel is simply the unit that controls the system and maintains constant temperature in the drying chamber. It is made up of the:

- Off and on switch

- Signal light

- Thermostat (thermocouple)

Principle of operation of the modified cabinet grain dryer: The dryer consists of a cabinet containing trays in which the grains to be dried are spread. After the grains are loaded, the cabinet is closed and heated air of about $35-40^{\circ} \mathrm{C}$ is blown across the grains. Heat is supplied by an electrical heating coil and hot air is blown from the heater housing to the drying chamber by the aid of a fan as shown in Fig. 5. The dryer also consists of a thermostat which turns off the machine if inlet temperature exceeds $40^{\circ} \mathrm{C}$. 


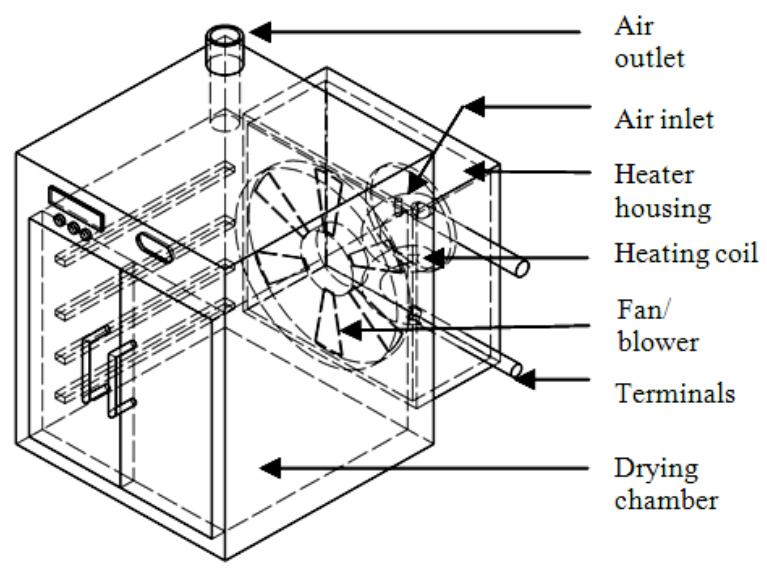

Fig. 5: Diagram showing the improved cabinet grain dryer

\section{RESULTS AND DISCUSSION}

\section{Advantages of the modified cabinet grain dryer over} the existing one:

- It is less costly

- It is cheap to maintain since the fan is the only moving component and can hardly become faulty

- Drying time of the grain is reduced

- The machine is ergonomic; operation of the machine does not require specialization

- The machine is safer to operate since the use of gas has been eliminated

- Time between two batches is reduced with the introduction of a trolley

- Energy for loading or unloading is reduced since the trays can be loaded and unloaded outside the cabinet

Maintenance and cost analysis:

Maintenance considerations for the modified cabinet grain dryer: The main purpose of maintenance is to extend the useful life of the equipment and machine to perform a predetermined level of maximum productivity. To ensure this, maintenance is required to be part of the user. It is then important to notify the user or operator on procedures in checking the daily working condition of the machine and preventive measures to take to avoid break down. The maintenance consideration and routine maintenance procedures for some components are outlined below.

The heater housing: There is a dire need to always ensure that the heater housing is rigidly mounted. This implies that all bolts and nuts should be tightened at regular intervals in case of slacking. Also worn out bolts should be replaced immediately.

The heating element: For the system to perform its function, the heating element must always be in a good condition. Hence proper connection must be ensured in case of break in circuit. For complete failure of heating element, replacement should be prompt.

The motor/fan: The motor may not need much regular attention but from time to time its coil will require maintenance operations such as cleaning and rewinding. Lubrication of the shaft at regular intervals will be necessary for reduction in friction. Fan blades may also require cleaning weekly. Trays

Maintenance may involve removal of grains from blocked holes on the wire gauze to facilitate effective drying.

Tyres: The trolley consists of tyres for easy movement. Preventive maintenance requires that the screws for the tyres are checked regularly and worn out tyres replaced.

General maintenance strategy: Generally the user of the machine will have to comply with some instructions and precautions to ensure longer life and smooth operation of the machine, more especially when the machine is not in use.

The whole equipment will require being kept in a safe and dry place to avoid rusting of component parts. Sometimes, lubrication of parts such as the trolley, tray grooves, motor shaft etc. with light oil may be necessary especially when the equipment will not be in use for a very long time. This is also done to prevent rusting of parts.

Depending on the environment, some of the system components like the motor may be isolated from the circuit for a safer storage strategy.

Cost analysis: The cost is analyzed taking each component into consideration. The total cost of this dryer is divided into material, production and miscellaneous costs.

Material cost for the frame and casting: The parameters used for the dimensions for the frame and casting of the machine are the length, L, width, W. and thickness, $\mathrm{T}^{[1]}$.

Production cost: This has to do with the cost incurred in the manufacture of the machine with the purchased materials. This involves complete machining and assembly of component parts. It includes labor cost, cost of machining components, cost of electrodes for 
welding and other consumables e.g. cutting and filling stones. The total production cost is estimated at $\$ 85$.

Miscellaneous cost: These are costs incurred in the course of the project other than the material and production costs. These include transportation, report writing and research cost. Total miscellaneous cost is $\$ 45$.

As shown from our research, there is every tendency that there should be improvement in the existing Cabinet Grain Dryer so as to eradicate the problem associated with the existing cabinet grain dryer. With this improvement, it will leads to optimization efficiency at low cost, reduction in time of drying and production of viable and quality grain.

\section{CONCLUSION}

Generally, grain drying is very important because it increases the storage life of cereal grains. The commonest methods of grain drying in our localities today include sun drying and the existing cabinet grain dryer. These methods have a lot of deficiencies in terms of drying speed, efficiency, productivity, quality and safety.

The improved design takes care of most of these problems. It is an effective tool for drying and its effectiveness exceeds all forms of drying used locally. The heater supplies the right quantity of heat and incorporates a fan which supplies the right quantity of air needed to distribute this heat evenly to all grains in the drying chamber. This makes drying faster and grains are moderately dried.

Additionally, drying of grains is safer since fire hazards are reduced owing to the use of gas in the previous design.

I recommend this design for small scale farming where the quantity of grain to be dried is not very large. In addition, the system is required to be kept clean and properly maintained to provide a more reliable and longer service life. Safety must also be ensured when operating a model construction of this design ${ }^{[1]}$.

\section{ACKNOWLEDGEMENT}

Acknowledgement is hereby accorded to $\mathrm{Mr}$. Njoku Ikenna for data collection, from both Ghana and Nigeria, for this project work.

\section{REFERENCES}

1. Baumeister, T. and L.S. Marks, 1967. Standard Handbook for Mechanical Engineers. 7th Edn., McGraw Hill, New York, pp: 7-38.

2. Beij, K.H., 1999. Pressure losses for fluid flow in 90 degree pipe bends. J. Res. Natl. Bureau Stand., 21: 1-18.

3. Brooker, F.H. et al., 1973. Drying Cereal Grain. 2nd Edn., John Wiley and Sons, New York.

4. Carl, W.H., 1967. Drying Farm Crops. 4th Edn., Agricultural Consulting Associates, Inc., UK.

5. Fellow, P.J., 1997. Industrial Application of Food Preservation Techniques. 4th Edn., McGraw Hill, New York.

6. Holman, J.P., 1998. Heat Transfer. 9th Edn., McGraw Hill, New York.

7. Moody, L.F., 1991. Friction factors for pipe flow. Trans. ASME., 66: 71-84

8. Pao, R.H.F., 1961. Fluid Mechanics. 4th Edn., John Wiley and Sons, New York, pp: 284.

9. Robert, H.P. and W.S. Don, 1997. Perry's Chemical Handbook. 7th Edn., McGraw Hill, New York, USA., ISBN: 10: 0070498415, pp: 2640.

10. Robert, L.M., 1979. Applied Fluid Mechanics. 2nd Edn., Bell and Howell, Ohio, pp: 379.

11. Sutherland and Ghaly, 1990. Grain Drying Techniques. Agricultural Research Institute, Phillipines, pp: 234. 